\title{
Synthesis of Carbonized Nano Mesoporous Sorbents Based on Vegetable Raw Materials
}

\author{
Azat Seitkhan \\ Institute of Combustion Problems, al-Farabi Kazakh National University, Almaty, Kazakhstan \\ *Corresponding Author: seithan@mail.ru
}

Copyright $@ 2013$ Horizon Research Publishing All rights reserved.

\begin{abstract}
This article presents the results of the synthesis of carbon nanomaterials: Nanoscale materials obtained by carbonization of waste agricultural products (apricot kernel, walnut, rice husk). The results of physico-chemical characteristics of the obtained nanomaterials. Physico-chemical parameters of the synthesis of carbonized sorbents based on plant raw material are investigated along with the properties of these sorbents. The data of FTIR, ESR spectroscopy \& BET- method, as well as electron microscopy are reported. It is stated that carbonized sorbents possess high specific surface area and porosity. Carboxylic, carbonyl, hydroxyl groups are detected on the surface of the synthesized sorbents. It is assumed that high sorption ability with respect to $\mathrm{Co}, \mathrm{Ni}, \mathrm{Pb}, \mathrm{Cd}, \mathrm{Cu}$ ions is connected with the formation of chelate complexes. It was shown that carbonized nanostructured sorbents are able to: adsorb cesium-137 (137Cs), strontium-90 (90Sr) \& lead-210 $(210 \mathrm{~Pb})$ successfully; reduce ions of gold (III) on the surface selectively; separate fusicoccine and similar biostimulators effectively; remove LPS-endotoxines from blood plasma selectively. They may be used as carriers to introduce probiotics into intestine thanks to formation of stable colonies on their developed surface. A method of preparation of honeycomb monoliths from carbonized rice husk with developed mesoporous structure via modification of the porous structure by silica leaching has been developed.
\end{abstract}

Keywords Nanotechnology, Nanomaterials, Carbonization, Electron Microscopy, Carbon Materials, Synthesis, Adsorbents

\section{Introduction}

Carbon adsorbents are widely used in various processes of purification of contaminants and recovery of valuable materials from liquids and gases. Increasingly, they are used in medicine, for example, to remove from the body fluids of individual components for cleaning the blood, as well as for the chromatographic separation of biomolecules[1].

Recently, carbon sorbents are widely used in various processes of purification from harmful contaminants, recovery of valuable substances from liquid and gaseous media, in medicine to clean the blood from the endo-and exotoxins, for detoxification of the gastro-intestinal tract and other purposes. The Institute of Combustion Problems, studies on the development of nanostructured sorbents, as well as the raw material used by waste rice husks, apricot, grape seed and walnut shells.

The aim of this study was to develop such sorbents, which would be characterized by high mechanical strength and withstand high pressures, which have large capacity and high wear resistance, enabling them to work for a long time. And also it was necessary to investigate the applicability of nanostructured carbon sorbents for the separation of biomolecules. In accordance with the objective addressed the following specific objectives: obtaining and testing of nanostructured carbon sorbent for the molecular-sieve chromatography of markers and testing of nanostructured carbon sorbent for the separation of protein-lipid complex, and plant bio-stimulator.

Industrial adsorbents based on activated carbons obtained from different types of organic materials: stone, brown coal, hard coal, peat, wood and its products, materials of animal origin. Non-traditional raw materials, which have not yet found wide application in industry, can be of various bones of fruit trees (apricot, peach, plum, cherry), grape seed and walnut shells, which are currently waste products.[2]

The need for low-cost sorbents that meet the requirements of production (a good sorption capacity, adjustable size and pore structure, etc.) leads to the development of new methods of obtaining sorbents. Activated carbon from plant material is cheap and readily available sorbent with a high porosity, strength, and reusable.

Processing of this type of stuff is usually performed in an oxygen-free environment in a vacuum or under nitrogen, at temperatures that are in the range from 150 to $900{ }^{\circ} \mathrm{C}$. The duration of isothermal holding at final temperature of pyrolysis ranges from 10-90 minutes. Analysis of the literature allows us to conclude that the temperature of pyrolysis of different types of plant materials are similar. In all cases, the output carbonizate decreases with increasing temperature, with most weight loss occurs in the range 
$150-500^{\circ} \mathrm{C}$. At the same time in the solid residues increases the carbon content, which at temperatures above $750^{\circ} \mathrm{C}$ higher than $90 \%$. Complete carbonation typically occurs at $850-900{ }^{\circ} \mathrm{C}[3-4]$.

The mechanism of progressive activation of plant carbonizate probably lies in the enlargement of pores of all types and the transformation of ultra micropor in the micropores, some fraction of micropores in supermicropory and mesopores, and mesopore large in the macropores. Since the content of ultra micropor carbonized high enough, the micropore volume increases with the degree of activation of at least $40-50 \%$ of ablation, and further because of these reasons is reduced. With regard to the specific surface area, calculated on the adsorption of $\mathrm{CO}_{2}$, then the appearance of large micro pores and supermicropor this adsorption proceeds by a mechanism not only to their bulk, and surface filling. Increasing ablation leads to a significant increase, both the volume and the effective pore radius.

In the production of activated carbons the main stages of the recycling process of the carbon material of plant origin are the " carbonation + activation " they provide the necessary formation of structural and physicochemical properties of the target products. The aim of this work is the selection of optimum conditions of carbonization and the study of the structure of obtained adsorbents. [5].

\section{Experimental}

\subsection{Synthesis of Carbonated Nanoscale Mesoporous Materials}

The process of carbonization of the samples was carried out under isothermal conditions. Inoculation of samples was performed in a rotating reactor, an inert atmosphere at a temperature of $100-900^{\circ} \mathrm{C}$, the argon flow rate $50 \mathrm{~cm}^{3} / \mathrm{min}$, contact time $60 \mathrm{~min}$. For the experiment took powdered fraction $(\mathrm{d}=2 \mathrm{~mm}, 4 \mathrm{~mm})$ and placed into the reactor.

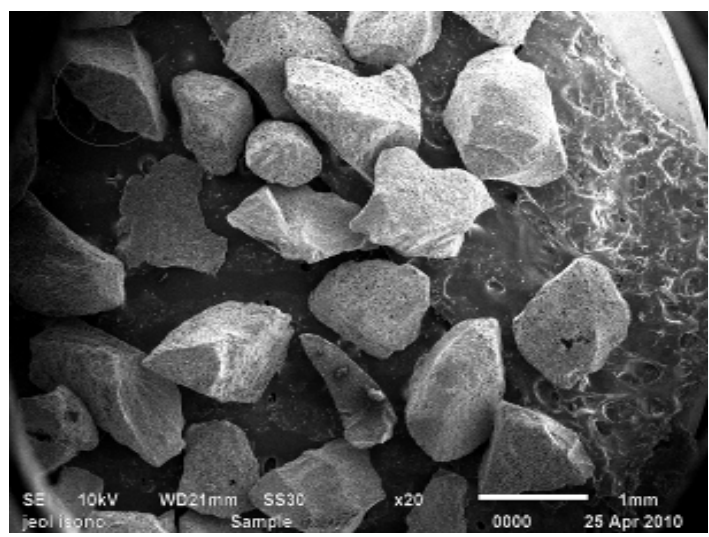

a

\subsection{Study of Physico-Chemical Characteristics of Nanomaterials}

The most important and reliable information about the structure of the carbonized carbon material can provide scanning electron microscopy. Scanning electron microscopy images of samples were obtained carbon material carbonized at different temperatures. Pictures carbonized samples are shown in Figures1 and 3.

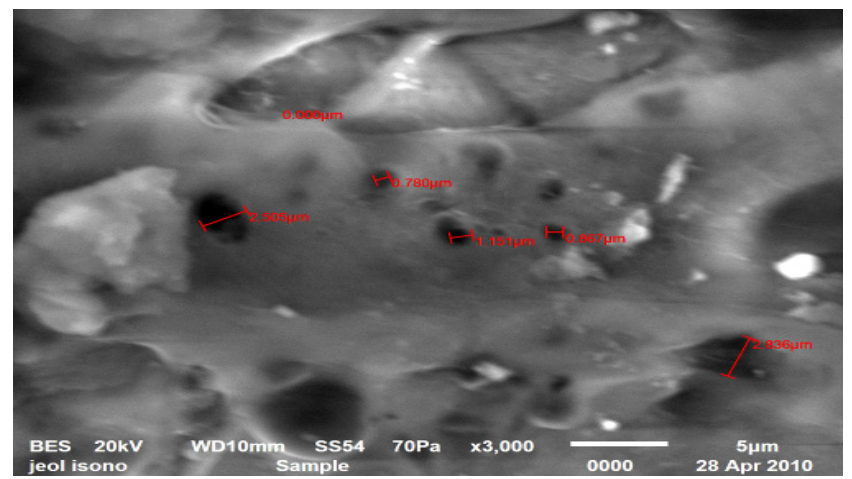

Figure 1. Electron micrograph of the surface of the particles apricot kernel before carbonization (scale 1:3000)

Before carbonization apricot kernel are undeveloped and very dense structure, has been a small amount of a diameter of $780 \mathrm{~nm}$ to $3000 \mathrm{~nm}$, as shown in Figure 2.

Found that the carbonization temperature $800^{\circ} \mathrm{C}$ where there is a significant loosening of the appearance of numerous pores larger than $200 \mathrm{~nm}$. Thus, a study produced the following results. Figure 2 a presented a snapshot of the entire surface of the particles of carbonized apricot pits at $800^{\circ} \mathrm{C}$. For the analysis of samples were collected, dispersed up to $1 \mathrm{~mm}$. The general form of the particles is shown in Figure 2b. As can be seen from this figure, the particles have a porous structure. Then, the depth of electron-microscopic study of the structure of the material carbonized at a temperature of $800^{\circ} \mathrm{C}$, under high magnification.

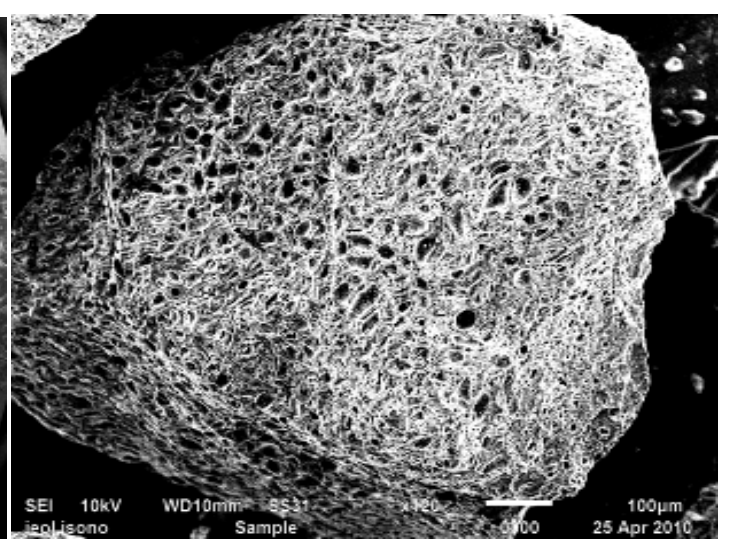

6

Figure 2. Electron micrograph of the surface of particles of carbonized samples with $800^{\circ} \mathrm{C}$ 


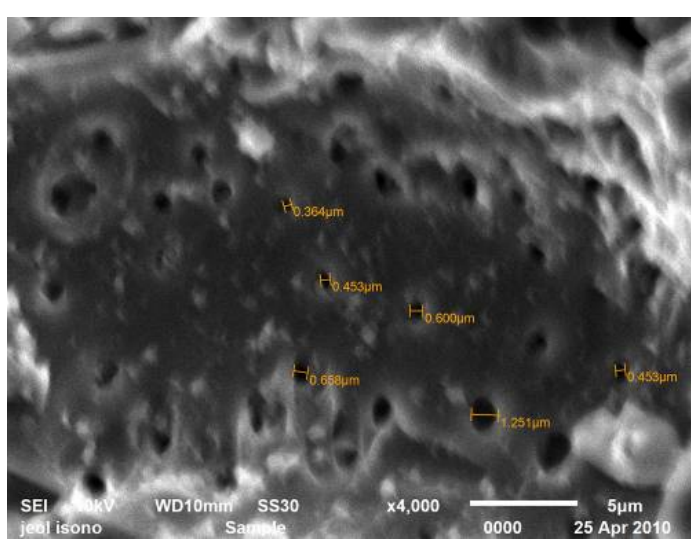

a

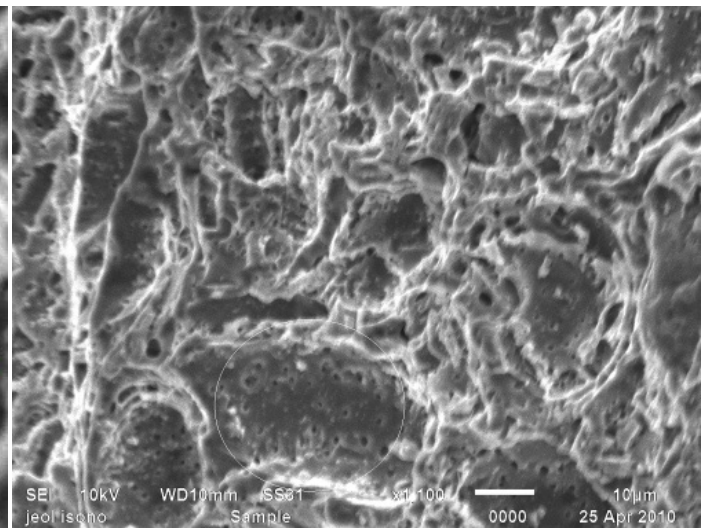

б

Figure 3. Electron micrograph of the sample carbonized at a temperature $800^{\circ} \mathrm{C}$ (scale $1: 1100$ )

Table 1. Specific surface area, porosity and density of the carbonized sorbent on the basis of rice husk and apricot kernel

\begin{tabular}{|c|c|c|c|c|c|c|}
\hline \multirow{2}{*}{$\begin{array}{c}\text { Temperatures } \\
\text { Carbonation }{ }^{\circ} \mathrm{C}\end{array}$} & \multicolumn{2}{|c|}{ Density, $\mathrm{g} / \mathrm{cm}^{3}$} & \multicolumn{2}{|c|}{ Porosity, $\mathrm{cm}^{3} / \mathrm{g}$} & \multicolumn{2}{|c|}{ The specific surface area, $\mathrm{m}^{2} / \mathrm{g}$} \\
\hline & rice husk & apricot kernel & rice husk & apricot kernel & rice husk & apricot kernel \\
\hline The initial samples & 1,58 & 1,74 & 0,19 & 0,21 & 238 & 240 \\
\hline 400 & 1,41 & 1,43 & 0,86 & 0,95 & 281 & 350 \\
\hline 450 & 1,21 & 0,92 & 1,02 & 0,98 & 456 & 560 \\
\hline 500 & 0,96 & 0,86 & 1,28 & 1,28 & 532 & 770 \\
\hline 550 & 0,76 & 0,61 & 1,56 & 1,39 & 673 & 780 \\
\hline 600 & 0,55 & 0,58 & 1,91 & 1,85 & 807 & 810 \\
\hline 650 & 0,46 & 0,50 & 2,16 & 1.86 & 910 & 815 \\
\hline 700 & 0,39 & 0,49 & 1,96 & 1,90 & 758 & 800 \\
\hline 750 & 0,36 & 0,47 & 0,95 & 1,87 & 684 & 810 \\
\hline 800 & 0,34 & 0,45 & 0,97 & 2.10 & 630 & 830 \\
\hline
\end{tabular}

With an increase up to 1100 times, you can see that on the surface of the sample contains large pores of $1500 \mathrm{~nm}$ to $3000 \mathrm{~nm}$ and on the borders of large pores are visible double-porous membrane (Figure 3a). It was interesting to examine the inner surface of large pores (Figure $3 b$ ). As seen in the micrographs, with a stronger increase of the inner surface of large pores are present pores ranging in size from $200 \mathrm{~nm}$ to $1300 \mathrm{~nm}$.

Thus, by using electron microscopy revealed that the carbon material, carbonized at a temperature $800^{\circ} \mathrm{C}$ is the most well-developed structure and porosity, and appearing at this temperature, carbon nanotubes attached to beads carbon material high strength and increase the specific surface area.

Figure 4 shows a nonlinear increase of the carbon concentration in the case of WB samples. This means that with the temperature rise the carbonization runs through different stages. At comparatively low heating temperatures, a pyrolytic removal of water mainly takes place, but at higher temperatures, a removal of low-molecular-weight carboniferous products and various tars takes place.

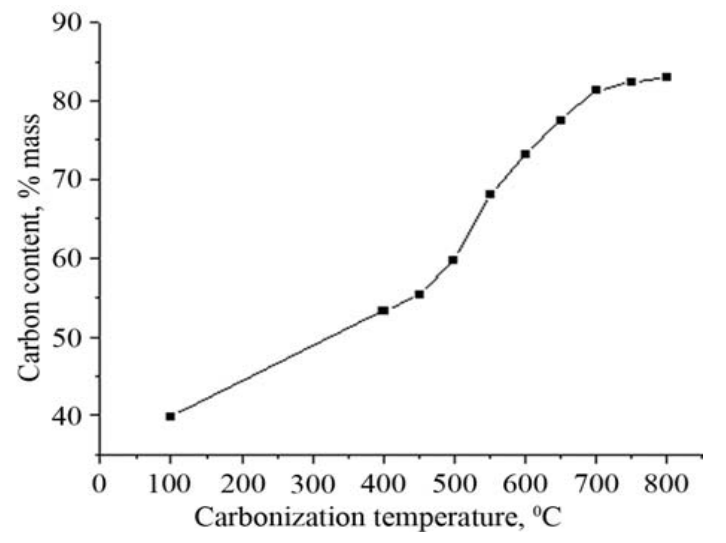

Figure 4. Dependence of carbon content on carbonization temperature

\subsection{Determination of Specific Surface Area, Porosity and Density of the Carbonized Material}

The specific surface area of the carbonized sorbent was studied by thermal desorption of argon. Table 1 shows the results of the specific surface area, porosity and density of 
the carbonized samples apricot kernel and rice husk. The highest specific surface area $\left(910 \mathrm{~m}^{2} / \mathrm{g}\right)$ sorbent has received at $650^{\circ} \mathrm{C}$. Further, when the temperature decreases the surface area of $758 \mathrm{~m}^{2} / \mathrm{g}$ (rice husk, carbonized at a temperature $700^{\circ} \mathrm{C}$ ) to $630 \mathrm{~m}^{2} / \mathrm{g}$ (rice husk, carbonized at a temperature $800^{\circ} \mathrm{C}$ ). If the initial density is rice husk -1.58 $\mathrm{g} / \mathrm{cm}^{3}$, for rice husk, carbonized at a temperature $400^{\circ} \mathrm{C}$, the figure is $-1.41 \mathrm{~g} / \mathrm{cm}^{3}$, and then the samples carbonized at a temperature $800^{\circ} \mathrm{C}$, reduced to a value of $0.34 \mathrm{~g} / \mathrm{cm}^{3}$. In this case the porosity is increased. Thus, in the initial porosity is rice husk $-0.19 \mathrm{~cm}^{3} / \mathrm{g}$, then with increasing carbonization temperature up to $400^{\circ} \mathrm{C}$, this index increased 4.5 -fold $(0.86$ $\mathrm{cm}^{3} / \mathrm{g}$ ), and carbonized at a temperature of sorbent $800^{\circ} \mathrm{C}$, this figure is $-0.97 \mathrm{~cm}^{3} / \mathrm{g}$ The density of the initial samples, based on the apricot kernel, is $-1.74 \mathrm{~g} / \mathrm{cm}^{3}$, with increasing carbonization temperature decreases the density of the sorbent in a 4 - fold, and at a temperature carbonization $800^{\circ} \mathrm{C}$, and the figure is $-0.45 \%$. Comparison of the porosity of the initial and carbonized at a temperature of sample apricot kernel $600^{\circ} \mathrm{C}$ shows that in the initial sample porosity is $-0.21 \mathrm{~cm}^{3} / \mathrm{g}$, and the samples carbonized at a temperature $600^{\circ} \mathrm{C}-2.10 \mathrm{~cm}^{3} / \mathrm{g}$. With further carbonization apricot kernel, porosity decreases, and the samples carbonized at a temperature $800^{\circ} \mathrm{C}$, the figure is $-1.84 \mathrm{~cm}^{3} / \mathrm{g}$. The specific surface area of the original apricot kernel $240 \mathrm{~m}^{2} / \mathrm{g}$, and with increasing temperature carbonization can see an increase in specific surface area of carbonized samples.

From these results, it became known that the maximum values of porosity and density of the samples shows rice husk, carbonized at a temperature of $650{ }^{\circ} \mathrm{C}$ as well. apricot kernel samples, carbonized at a temperature $800^{\circ} \mathrm{C}$

Thus, according to the results of the experiments found that the carbonization of the samples apricot kernel and rice husk, increases the specific surface area, porosity and a decrease in the density of the final product.

\section{Conclusion}

The results by electron microscopy revealed that the carbon material, carbonized at a temperature $800^{\circ} \mathrm{C}$ is the most well-developed structure and porosity, and appearing at this temperature, carbon nanotubes attached to beads carbon materials high strength and increase the specific surface area.

From these results, it became known that the maximum values of porosity and density of the samples shows rice husk, carbonized at a temperature of $650^{\circ} \mathrm{C}$ as well. apricot kernel samples, carbonized at a temperature $800^{\circ} \mathrm{C}$.

Thus, according to the results of the experiments found that the carbonization of the samples rice husk and apricot kernel, increases the specific surface area, porosity and a decrease in the density of the final product.

\section{REFERENCES}

[1] A. Andrievsky, R.A,.RatulyaA. Nanostructured materials. Moscow: The Academy, 2005. P192.

[2] A.R. Kerimkulova, B.B. Mansurova, M.K. Gilmanov, Z.A. Mansurov, Nanoporous CarbonSorbent for Molecular_Sieve Chromatography of Lipoprotein Complex.// Russian Journal of Physical Chemistry A, 2011, Vol. 85, No. 6, pp. 1004-1007.

[3] Mansurov Z.A. Some Applications of Nanocarbon Materials for Novel Devices / / R. Gross et al (eds.), Nonoscale-Devices Fundamentals, Springer, 2006. P. 355-368.

[4] Mansurova R.M Carbon-containing composition. Chemistry and chemical technology.Modern Problems. Almaty: XXI Century, 2001. P 152-175.

[5] Kudaybergenov K., Ongarbayev Y., Mansurov Z., Doszhanov Y. Study on the effectiveness of thermally treated rice husks for petroleum adsorption // Journal of Non-Crystalline Solids. - 2012. - Vol. 358. - P. 2964-2969. 